Revista Eureka sobre Enseñanza y Divulgación de las Ciencias

ISSN: 1697-011X

revista.eureka@uca.es

Universidad de Cádiz

España

\title{
Iniciación a las prácticas científicas en Educación Infantil: aprendiendo sobre el sistema digestivo por indagación basada en modelos
}

Cruz-Guzmán Alcalá, Marta; Martínez Maqueda, Esther

Iniciación a las prácticas científicas en Educación Infantil: aprendiendo sobre el sistema digestivo por indagación basada en modelos

Revista Eureka sobre Enseñanza y Divulgación de las Ciencias, vol. 19, núm. 1, 2022

Universidad de Cádiz, España

Disponible en: https://www.redalyc.org/articulo.oa?id=92068491004

DOI: https://doi.org/10.25267/Rev_Eureka_ensen_divulg_cienc.2022.v19.i1.1202 
Experiencias, recursos y otros trabajos

\section{Iniciación a las prácticas científicas en Educación Infantil: aprendiendo sobre el sistema digestivo por indagación basada en modelos}

Scientific practical initiation in Kindergarten: the digestive system through inquiry and modeling based learning

Marta Cruz-Guzmán Alcalá

Departamento de Didáctica de las Ciencias Experimentales

y Sociales, Universidad de Sevilla, España

mcruzguzman@us.es

iD https://orcid.org/0000-0003-0018-3620

Esther Martinez Maqueda

Estudiante de Máster de la Universidad de Sevilla, España

esthermm98@gmail.com
DOI: https://doi.org/10.25267/

Rev_Eureka_ensen_divulg_cienc.2022.v19.i1.1202

Redalyc: https://www.redalyc.org/articulo.oa?

$\mathrm{id}=92068491004$

Recepción: 16 Marzo 2021

Revisado: 06 Junio 2021

Aprobación: 13 Septiembre 2021

\section{Resumen:}

Se describe una intervención docente realizada en un aula con 24 estudiantes de 5 años, basada en una actividad experimental de carácter indagador que se desarrolla con caracoles y utiliza modelos en su versión instrumental para hacer evolucionar los modelos científicos escolares sobre el proceso de la digestión. Para conocer los aprendizajes desarrollados por los escolares, se realizan entrevistas iniciales, cuyas respuestas se analizan y categorizan mediante la combinación de métodos de evaluación intere intra-jueces, y se comparan con las obtenidas en la fase de comunicación de la indagación realizada. En general, se observó una evolución positiva en el aprendizaje de los escolares, así como el desarrollo de emociones positivas al hacer ciencia. Se concluye que, con intervenciones como la llevada a cabo, es posible llevar las prácticas científicas al aula de Educación Infantil.

Palabras clave: Sistema digestivo, Educación Infantil, Indagación, Modelos científicos, Prácticas científicas.

\section{Abstract:}

We present a didactical approach, that has been implemented in a kindergarten classroom with 24 children (5-6 years old). It was an inquiry-based proposal with snails which uses modeling to improve digestive system scientific models. To know what the learners have actually learned, initials interviews were made. Final data came from the comunication phase in the inquiry activity. The responses were analyzed and categorizated by intra- and inter-rater agreement. Initial and final analysis were compared. In general, we observed a positive development of the learnings and positive emotions when making science. It is concluded that this type of didactical approaches is able to take scientific practices to kindergarten classrooms.

KEYWORDS: Digestive system, Kindergarten, Inquiry-based learning, Scientific models, Scientific practices.

\section{INTRODUCCIÓN}

Desde la Didáctica de las Ciencias se defienden las prácticas científicas en la enseñanza de las ciencias desde las primeras etapas educativas (Mosquera et al. 2018). Pero el desarrollo de secuencias didácticas que las fomenten sigue siendo escaso en las aulas de Educación Infantil (EI). Así, Sung y Oh (2018) evidenciaron la falta de literatura sobre experiencias relativas a la modelización llevadas a cabo por los escolares de los niveles educativos iniciales, frente a la mayor atención prestada en los grados superiores.

Con el fin de contribuir a la reducción de la brecha entre las recomendaciones de la Didáctica de las Ciencias y la realidad del aula, en este trabajo se muestra cómo evolucionan los modelos científicos escolares 
del alumnado de 5 años cuando en el aula se implementa un proceso instructivo basado en una indagación estructurada, en la que se utilizan modelos en su versión instrumental para trabajar el sistema digestivo.

La modelización les puede ayudar a dar sentido al mundo natural de una manera consciente (Samarapungavan, Tippins y Bryan, 2015) y a desarrollar argumentos, hipótesis y explicaciones científicas incipientes (Harrison y Treagust, 2000). Este trabajo persigue contribuir y ejemplificar el desarrollo de una educación científica en EI en la que el alumnado aprenda ciencia, sobre ciencia y a hacer ciencia (Justi, 2006).

\section{MARCo TEÓRICo}

\section{Las prácticas científicas de la indagación y modelización en Educación Infantil}

Las prácticas científicas, como indagación y modelización, ayudan al alumnado a construir sus modelos científicos escolares, favoreciendo una actitud positiva y crítica hacia la ciencia, siendo el lenguaje y el rol de comunidad cruciales para su aprendizaje.

Con respecto a las estrategias de enseñanza de ciencia basadas en la indagación, Banchi y Bell (2008) proponen cuatro tipos de actividades según el nivel de indagación que promuevan (p. 27): (i) confirmatoria, donde los estudiantes confirman un fenómeno o explicación que conocen de antemano; (ii) estructurada, donde el profesor propone la pregunta y el procedimiento que se ha de seguir en la indagación; (iii) guiada, donde los estudiantes investigan una pregunta del profesor con su propia planificación, y (iv) abierta, donde los estudiantes investigan sus propias preguntas con sus propios procedimientos.

En EI, en este trabajo, defendemos actividades de indagación estructuradas, ya que, a estas edades, el alumnado necesita el apoyo instructivo de los docentes, y, a su vez, oportunidades para involucrarse de forma sostenida con el mismo conjunto de ideas (Couso 2014). En concreto, este tipo de actividades puede ser beneficioso para los docentes de Educación Infantil que se inician en las actividades indagadoras, ya que les permite una mayor autoconfianza al enfrentarse a este tipo de actividades, sobre las que suelen presentar cierta resistencia (Díaz-Moreno, 2017; Wheeler, Bell, Whitworth y Maeng, 2015).

Por su parte, Solé-Llussà et al. (2018) describe las fases realizadas por alumnado de Educación Infantil y Primaria para llevar a cabo experiencias escolares basadas en la indagación (sobre los seres vivos, salud y cuerpo humano, materia y energía, y el entorno y su conservación). Estas fueron: a) planteamiento de pregunta investigable; b) formulación de hipótesis; c) planificación de investigación en la que recoger datos; d) recogida e interpretación de datos; y e) explicación de los mismos, dando respuesta a la pregunta inicial.

Con respecto a la modelización, Oliva (2019) ha sintetizado los distintos significados de modelización en la bibliografía sobre educación científica del siguiente modo: (i) como progresión de modelos; (ii) como práctica científica; (iii) como competencia; (iv) en su dimensión instrumental; y (v) como enfoque didáctico.

Los modelos científicos son construcciones abstractas que sirven para representar el mundo, comprender y predecir los fenómenos de este, ajustándose a la realidad (Gómez et al. 2007; Pérez et al., 2018). Con los modelos podemos entender e interpretar el mundo, y esto nos permite comunicar esas interpretaciones. Hablamos de ciencia escolar cuando se construyen modelos teóricos entendibles para los estudiantes (Adúriz-Bravo 2001). En este contexto, los modelos científicos escolares son aquellas representaciones simplificadas de objetos, fenómenos, procesos, ideas o sistemas de la realidad física, que los estudiantes elaboran para explicar y hacer predicciones sobre estos (Acevedo-Díaz, García-Carmona, Aragón-Méndez y Oliva-Martínez, 2017). En Educación Infantil, el uso de maquetas o modelos físicos ha mostrado ser efectivo para que los niños ${ }^{[1]}$ construyan modelos científicos incipientes sobre fenómenos de la naturaleza (Rodríguez-Moreno, de Pro y de Pro, 2020).

En la indagación basada o centrada en modelizar (IBM), muy estudiada por diversos autores (Couso 2014, Martínez-Chico et al. 2015, Schwarz et al. 2009, Stewart et al., 2005), se revisan modelos que sirven 
como referencia para generar hipótesis comprobables con experiencias reales o mentales, y para interpretar datos (pruebas del modelo). Así, se describen cinco conversaciones que sustentan la indagación centrada en modelizar: establecer los parámetros generales; organizar lo que sabemos y queremos saber; generar hipótesis; buscar pruebas y construir argumentos.

\section{La modelización en su dimensión instrumental, modelos como recursos metodológicos.}

Los modelos han de emplearse en sintonía con un plan más general para dar sentido a las secuencias de enseñanza-aprendizaje en las que se incluyen (Oliva, 2019). Entre todos los tipos de modelos en su dimensión instrumental descritos en la bibliografía en los diversos niveles educativos (modelos simbólicos, teóricos, etc.), en EI destacaríamos los siguientes, por su aplicabilidad en el aula:

(i) Modelos icónicos: son representaciones concretas y simplificadas de un objeto, fenómeno o sistema mediante dibujos, escenificaciones, maquetas, simulaciones por ordenador, etc. (Aragón-Núñez et al. 2018) para hacer perceptible o reproducir un aspecto determinado del mismo. La representación de una molécula mediante pequeñas bolas unidas con palitos, o una maqueta del Sistema Solar serían ejemplos de este tipo de modelos científicos escolares (Galagovsky y Adúriz-Bravo 2001). Estos modelos pueden ser: i.a) a escala, al ser utilizados para describir el aspecto, la forma o estructura de un objeto o sistema, por lo que están orientados sobre todo a representar en vez de a explicar el funcionamiento del objeto o sistema representado; i.b) o pueden representar múltiples procesos y/o conceptos: En esta tipología encontramos modelos de conceptosproceso y simulaciones virtuales (Harrison y Treagust 2000), tales como las animaciones con applets.

(ii) Modelos analógicos concretos: se utilizan para que el alumnado relacione analógicamente ideas científicas con conceptos o situaciones (ejemplos) que ya tiene en su estructura cognitiva; esto es, apela a componentes del sentido común o de la vida cotidiana (pensamiento concreto) (Piaget e Inhelder 1959). Ejemplos de este tipo de modelos sería utilizar el funcionamiento de una cámara fotográfica para explicar el funcionamiento del ojo (Galagovsky y Adúriz-Bravo 2001) o las uniones entre las manos para explicar la fuerza de un enlace químico. Gilbert (2004) sostiene que la analogía consigue la identificación de características similares entre algo que es conocido por el alumnado y otro fenómeno o sistema que se quiere conocer, y, entre otros, pueden ser modelos verbales, gestuales o visuales. Así, puede tratarse de dos sistemas muy distintos, pero con alguna característica en común (el ojo humano y una cámara fotográfica, en el ejemplo anterior).

\section{¿Por qué enseñar y aprender sobre el sistema digestivo en Educación Infantil?}

El tema es importante en la infancia, cuando los niños construyen una representación del interior de su organismo (Cubero, 1988, De Alba y Ramos 2020). Además, los niños tienen una experiencia directa con el sistema digestivo, sensaciones y percepciones que les motivan y les permiten realizar una representación sobre su cuerpo. El curriculum oficial así lo refleja, en el área de Conocimiento de si mismo y autonomía personal de la Orden ECI/3960/2007, de 19 de diciembre (B.O.E. 2008), con uno de sus objetivos, «Conocer y representar su cuerpo, algunos de sus elementos y funciones, descubriendo sus posibilidades de acción y de expresión» (p. 9).

Además, en el área de Conocimiento del entorno expone en el bloque 2, Acercamiento a la naturaleza, el contenido «Detección de algunas características, comportamientos, funciones y cambios en los seres vivos» (p. 16). Por último, ente los criterios de evaluación de etapa, destaca:

Igualmente, a lo largo del segundo ciclo, se observará si detecta algunas funciones y comportamientos de los seres vivos refiriéndose, por ejemplo, al modo en que se alimentan algunos animales (nutrición), [...] y si las relaciona con el ciclo vital, si observa y habla de los cambios que algunos elementos y seres de la naturaleza experimentan. (p. 18) 


\section{¿Qué experiencias que utilicen la indagación y la modelización se han implementado con el alumnado de Educación Infantil? Antecedentes.}

Este trabajo se enmarca en una realidad de aula de EI que se está desarrollando actualmente en nuestro contexto, con propuestas para tratar contenidos de ciencia a través de prácticas científicas. Mazas, Cascarosa y Mateo (2021) trabajaron un proyecto sobre el corazón partiendo de la curiosidad de los niños, utilizando observaciones sensoriales (en 3 años) y relacionándolas con explicaciones y conclusiones anteriores (en 5 años). El alumnado utilizó prácticas científicas de indagación, modelización y argumentación de forma exitosa, tanto por el incremento de sus conocimientos y emociones positivas, como por el desarrollo del pensamiento crítico y científico. Por su parte, Calo, García-Rodeja y Sesto (2021) llevaron al aula de 4 años la comunicación como eje fundamental para el aprendizaje. Los niños hablaban, actuaban y pensaban sobre la electricidad. La maestra ejercía de guía, ofreciendo materiales, experiencias y retos para que ellos mismos construyeran y reconstruyeran ideas y modelos. Además, en la tabla 1 se presenta un resumen de propuestas de enseñanza que trabajan las prácticas científicas en el aula de EI. 
TABLA 1

Ejemplos de experiencias en las que se desarrollan las prácticas científicas en Educación Infantil

\begin{tabular}{|c|c|c|c|}
\hline Cita & Temática & $\begin{array}{c}\text { Práctica } \\
\text { científica }^{1}\end{array}$ & Resultado de aprendizaje del alumnado \\
\hline $\begin{array}{l}\text { Cruz-Guzmán, } \\
\text { García-Carmona } \\
\text { y Criado (2017) }\end{array}$ & $\begin{array}{l}\text { Cambios de } \\
\text { estado }\end{array}$ & $\begin{array}{l}\text { Indagación } \\
\text { (preguntas- } \\
\text { predicciones) }\end{array}$ & $\begin{array}{l}\text { Alumnado de 1er y } 2 \text { do ciclo realizaron predicciones y } \\
\text { aprendieron indagando. Desarrollo de emociones } \\
\text { positivas (implicación y motivación). }\end{array}$ \\
\hline $\begin{array}{l}\text { Herakleioti y } \\
\text { Pantidos (2016) }\end{array}$ & Sombras & Indagación & $\begin{array}{l}\text { Alumnado hizo predicciones, y las comprobaron con } \\
\text { sus cuerpos como obstáculos a la luz. Además, } \\
\text { manejaron y modificaron variables, tales como la } \\
\text { dirección de la luz y posiciones relativas de la fuente de } \\
\text { luz y del obstáculo. }\end{array}$ \\
\hline $\begin{array}{l}\text { Canedo-Ibarra } \\
\text { et al. (2012) }\end{array}$ & Seres vivos & $\begin{array}{l}\text { Indagación y } \\
\text { Modelización } \\
\text { (práctica } \\
\text { científica) }\end{array}$ & $\begin{array}{l}\text { El docente guía y cuestiona al alumnado en la } \\
\text { elaboración de sus justificaciones, a través de un } \\
\text { enfoque de enseñanza colaborativa que utiliza el } \\
\text { aprendizaje por descubrimiento guiado y exploratorio } \\
\text { (el alumnado considera variables, expone sus hipótesis } \\
\text { y predicciones y las evalúa al discutir los resultados). }\end{array}$ \\
\hline $\begin{array}{l}\text { Siry y Kremer } \\
(2011)\end{array}$ & Arcoíris & $\begin{array}{l}\text { Modelización } \\
\text { (práctica } \\
\text { científica) }\end{array}$ & $\begin{array}{l}\text { La intervención docente es un proceso creativo de } \\
\text { construcción con ideas, interacciones (entre iguales y } \\
\text { con la docente) y experiencias. Entre otros, se } \\
\text { respondió a « ¿Son los arcoíris sólidos?", "¿Se pueden } \\
\text { agarrar o nos podemos deslizar sobre ellos?». }\end{array}$ \\
\hline $\begin{array}{ll}\text { De Alba } \quad y \\
\text { Ramos (2020) }\end{array}$ & $\begin{array}{l}\text { Sistema } \\
\text { circulatorio } \\
\text { (corazón, } \\
\text { arterias } \quad y \\
\text { venas) }\end{array}$ & $\begin{array}{l}\text { Modelización } \\
\text { (práctica } \\
\text { científica y } \\
\text { dimensión } \\
\text { instrumental) }\end{array}$ & $\begin{array}{l}\text { La realización de dibujos, siluetas del cuerpo, } \\
\text { observación (nervaduras de plantas, escucha de corazón } \\
\text { humano con estetoscopio) y la manipulación de ciertos } \\
\text { órganos (corazones de pollo), fueron elementos } \\
\text { fundamentales para construir explicaciones sobre cómo } \\
\text { llega la sangre a los órganos del cuerpo. }\end{array}$ \\
\hline $\begin{array}{l}\text { Rodríguez- } \\
\text { Moreno, de Pro } \\
\text { y de Pro }(2020)\end{array}$ & Electricidad & $\begin{array}{l}\text { Modelización } \\
\text { (dimensión } \\
\text { instrumental) }\end{array}$ & $\begin{array}{l}\text { Se escenificó un circuito bumano (unión de personas con } \\
\text { elementos de cartulina en el pecho). Desarrollo de } \\
\text { emociones positivas («las actividades más divertidas») y } \\
\text { resultados de aprendizaje satisfactorios, aunque no } \\
\text { construyeron un modelo deseable de corriente eléctrica, }\end{array}$ \\
\hline $\begin{array}{l}\text { Padial-Ruz et al. } \\
(2017)\end{array}$ & Nutrición & $\begin{array}{l}\text { Modelización } \\
\text { (dimensión } \\
\text { instrumental) }\end{array}$ & $\begin{array}{l}\text { Utilizaron maquetas (dentadura gigante a limpiar con } \\
\text { cepillo e hilo dental; pirámide alimenticia, en la que se } \\
\text { colocaban alimentos encontrados en un circuito). } \\
\text { Resultados favorables al comparar una evaluación } \\
\text { previa y una final, observaron una mejora significativa. }\end{array}$ \\
\hline $\begin{array}{l}\text { Ashbrook } \\
(2012)\end{array}$ & $\begin{array}{l}\text { Formación } \\
\text { cráteres } \\
\text { lunares }\end{array}$ & $\begin{array}{l}\text { Modelización } \\
\text { (dimensión } \\
\text { instrumental) }\end{array}$ & $\begin{array}{l}\text { Describe (no implementa) una sencilla actividad de } \\
\text { formación de cráteres lunares sobre un recipiente con } \\
\text { arena, dejando caer bolas de diferentes pesos o con } \\
\text { distintas fuerzas de lanzamiento. }\end{array}$ \\
\hline Fuentes (2016) & $\begin{array}{l}\text { E1 cuerpo } \\
\text { humano }\end{array}$ & $\begin{array}{l}\text { Modelización } \\
\text { (dimensión } \\
\text { instrumental) }\end{array}$ & $\begin{array}{l}\text { Crearon un cuerpo humano gigante (a tamaño natural) } \\
\text { para trabajar las partes externas del cuerpo (cabeza, } \\
\text { cara, partes del tronco, extremidades y sus partes) e } \\
\text { internas (algunos órganos y esqueleto). }\end{array}$ \\
\hline
\end{tabular}

${ }^{1}$ La modelización como progresión o construcción de modelos científicos escolares no se detalla, ya que en todas las publicaciones acompaña a la práctica científica predominante (excepto Ashbrook 2012).

\section{OBJetivos}

La Didáctica de las Ciencias defiende las prácticas científicas, pero en las aulas de EI los docentes no las desarrollan tanto como sería deseable. En este trabajo, se plantean los siguientes objetivos: 
i) Diseñar e implementar en EI una actividad experimental de carácter indagador con caracoles, que utilice los modelos como recursos instrumentales para hacer evolucionar los modelos científicos escolares del alumnado.

ii) Tras la implementación de la propuesta didáctica, comprobar la evolución de los modelos científicos escolares del alumnado de 5 y 6 años sobre el sistema digestivo.

\section{ConTeXto Y Metodología}

\section{Participantes}

Nuestra propuesta se ha implementado en una de las aulas de 5 años de un colegio público de la provincia de Sevilla. Esta aula cuenta con 25 estudiantes, 11 niños y 14 niñas. Uno de los niños presenta un retraso madurativo, otra niña tiene trastorno del lenguaje y además muestra rasgos en su comportamiento del Trastorno del Espectro Autista, aunque no tiene diagnóstico del mismo. Los participantes del estudio fueron 24 estudiantes, debido a la falta de asistencia de un niño durante la semana en la que se desarrolló la intervención docente.

\section{Proceso instructivo}

Se ha diseñado una actividad experimental de carácter indagador que utiliza la modelización en su perspectiva instrumental. Su diseño se muestra al mismo tiempo que se describe su implementación en el aula, en el apartado de resultados.

La docente participó en el diseño de la secuencia didáctica planteada y la desarrolló en el aula. Las familias no intervinieron en el proceso. Se emplearon cuatro sesiones, además de las dos necesarias para conocer los modelos científicos escolares iniciales y finales.

\section{Instrumentos y proceso de análisis}

En este trabajo se presentan 5 preguntas (tabla 2), que forman parte de un guion abierto más amplio, para realizar entrevistas al alumnado, antes de una intervención didáctica. Estas preguntas pretendían conocer los modelos científicos escolares del alumnado antes de la implementación de la actividad descrita. Las entrevistas se realizaron en el tiempo libre y de forma individual. Se grabaron con audios y las respuestas fueron transcritas. 
TABLA 2

Preguntas implementadas para conocer los modelos científicos escolares del alumnado

\begin{tabular}{|c|c|}
\hline Pregunta que hacemos & Qué queremos averiguar: Si conocen que... \\
\hline $\begin{array}{l}\text { Mostrando una foto del sistema digestivo, } \\
\text { se pregunta: ¿Sabéis qué son y cómo se } \\
\text { llama cada parte? ¿Qué ocurre en cada } \\
\text { uno? }\end{array}$ & $\begin{array}{l}\text { Boca, esófago, estómago e intestino son los órganos del } \\
\text { apartado digestivo y sus funciones: en la boca se produce la } \\
\text { masticación y deglución; en el esófago se conduce el alimento } \\
\text { mezclado con la saliva al estómago; en él se lleva a cabo la } \\
\text { digestión; en el intestino se absorben los nutrientes y se } \\
\text { separan las sustancias útiles de las no aprovechables. }\end{array}$ \\
\hline $\begin{array}{l}\text { ¿Nuestra boca está seca o mojada por } \\
\text { dentro? ¿Por qué está mojada? ¿Para qué } \\
\text { creéis que tenemos saliva en la boca? }\end{array}$ & $\begin{array}{l}\text { E1 líquido que tenemos en la boca (saliva) se mezcla con el } \\
\text { alimento facilitando la deglución (ayudándonos a tragar). }\end{array}$ \\
\hline $\begin{array}{l}\text { ¿Qué hacemos para cuidar los dientes? } \\
\text { ¿Qué ocurre si no los lavamos? }\end{array}$ & $\begin{array}{l}\text { Para cuidar los dientes hay que lavárselos, evitando infecciones } \\
\text { y enfermedades (picaduras o caries). }\end{array}$ \\
\hline $\begin{array}{l}\text { Si te comes algo por la boca (una chuche, } \\
\text { una zanahoria, espinacas...), ¿creéis que } \\
\text { parte de ese alimento puede salir por la } \\
\text { caca o todo se queda dentro de nosotros? }\end{array}$ & $\begin{array}{l}\text { Todo lo que comemos no lo absorbe nuestro cuerpo, sino que } \\
\text { parte de los alimentos la expulsamos al defecar. }\end{array}$ \\
\hline
\end{tabular}

Para conocer la evolución de los modelos científicos escolares, al finalizar la actividad experimental, en la fase de comunicación de conclusiones, se llevó a cabo una teatralización con marionetas, en la que Caperucita Roja hace preguntas a los estudiantes, dándoles dos opciones de respuesta. Para elegir la opción con la que estaban de acuerdo, debían levantar la mano o ponérsela en la cabeza. Para evitar que copiaran las respuestas, tuvieron que contestar con los ojos cerrados. Las preguntas realizadas se describen en la tabla 7 .

Dado el carácter cualitativo e interpretativo del estudio, las respuestas del alumnado antes de la intervención educativa fueron analizadas y categorizadas mediante métodos de evaluación intra-juez y, en menor extensión, inter-juez (Padilla 2002). El proceso intra-juez fue llevado a cabo por una de las autoras durante un mes, y llevó a una primera categorización de las respuestas del alumnado, siguiendo procesos iterativos e inductivos. El análisis inter-juez fue llevado a cabo por las dos autoras del trabajo. Consistió en la discusión sobre los casos en los que la autora que realizó el proceso intra-juez tenía dudas sobre la categorización (alrededor de un 10\% de las respuestas). Se analizaron y discutieron hasta obtener el sistema de categorías definitivo, que establece distintos niveles de formulación y la proporción del alumnado en cada uno de ellos. Para facilitar su comprensión y contribuir a la objetividad del análisis, se presentan además descriptores de baja inferencia o ejemplos de respuestas del alumnado.

\section{Resultados}

\section{Diseño e implementación de una actividad experimental de carácter indagador que utiliza la modelización en su perspectiva instrumental.}

La finalidad de la actividad propuesta es que los escolares construyan de manera colaborativa su modelo escolar sobre el sistema digestivo, iniciándose para ello en las prácticas científicas. A continuación, se describen las fases seguidas en el proceso instructivo.

1) Contextualización. Se comenzó hablando de los caracoles, como animales que se arrastran por el suelo, tienen una concha que siempre va con ellos y los protege. Se les preguntó: ¿Sabéis lo que comen? Algunos 
respondieron «lechuga», otros «plantas»; todos coincidían en que comían vegetales. Se les dijo que comían lechuga, tomate, harina... Por último, se les preguntó si sabían algo más acerca de ellos y tras esta introducción, se les presentaron los materiales necesarios para realizar el experimento. En este momento, se les formuló la pregunta para comenzar la indagación.

2) Pregunta de indagación. ¿Qué ocurrirá con la caca de unos caracoles si les damos de comer harina con colorante rojo y con la de otros si les damos de comer harina con colorante verde?

3) Hipótesis de los escolares. Obtuvimos 24 hipótesis. La mayoría de escolares (23/24) coincidieron en la misma hipótesis respecto al color del excremento cuando los caracoles comían harina con colorante verde, sería verde. Sin embargo, tuvieron distintas hipótesis sobre el color cuando los caracoles tomaran harina con colorante rojo (tabla 3), pues antes de llevar a cabo el experimento y formular sus hipótesis vieron que la comida era rosa (mezcla de harina con colorante rojo), aunque oralmente la describiéramos como «harina con colorante rojo». Es por esto que algunos estudiantes, al ver la comida rosa, pensaron que el excremento sería rosa; pero otros, al oír que la comida era harina con colorante rojo, pensaron que sería de color rojo.

TABLA 3

Frecuencia de cada hipótesis sobre el color del excremento del caracol tras ingerir harina con colorante rojo

\begin{tabular}{lc}
\hline Hipótesis sobre el color del excremento & Frecuencia \\
\hline Color del colorante que forma parte de la comida (rojo). & $10 / 24$ \\
Mismo color que el alimento que come (rosa). & $6 / 24$ \\
Dos colores, del mismo color y del color del colorante en la comida (rosa y rojo). & $5 / 24$ \\
De colorines & $2 / 24$ \\
Rosa y caca rosa & $1 / 24$ \\
\hline
\end{tabular}

4) Planificación de la experiencia. Para preparar la comprobación de las hipótesis, el alumnado la planificó teniendo en cuenta:

4.i) Materiales necesarios: 39 caracoles vivos; $100 \mathrm{~g}$. de harina de trigo; $15 \mathrm{ml}$. de colorante alimenticio rojo; $15 \mathrm{ml}$. de colorante alimenticio azul; $15 \mathrm{ml}$. de colorante alimenticio amarillo; 2 recipientes de plástico transparente; 1 metro de film transparente; 1 tijeras; 1 caja de ceras de colores; 2 vasos de plástico; 2 cucharas de metal; y 1 palillo.

4.ii) Construcción de tablas de recogida de datos. Por ser esta la primera actividad de este tipo desarrollada en el aula y por la edad del alumnado, se repartieron las tablas con los valores de la variable independiente, siendo ellos quienes dibujaron el valor de la variable dependiente. En este momento, el alumnado rellenó las tablas con sus hipótesis.

5) Comprobación experimental de sus hipótesis. Para comprobar sus hipótesis, se dividió al alumnado en dos grupos, el verde y el rojo. El primero se encargó de preparar el recipiente de plástico de caracoles con harina y colorante verde (mezcla de colorantes azul y amarillo) y el equipo rojo preparó el recipiente de caracoles con harina y colorante rojo. La maestra tapó el recipiente con film transparente para que no se escaparan los caracoles y se hicieron agujeros con un palillo para que pudieran respirar. Ambos recipientes estuvieron accesibles junto a la mesa de la maestra, para facilitar la observación en los días posteriores. Tras tres días, se solicitó al alumnado que dibujara los resultados observados (figura 1). 


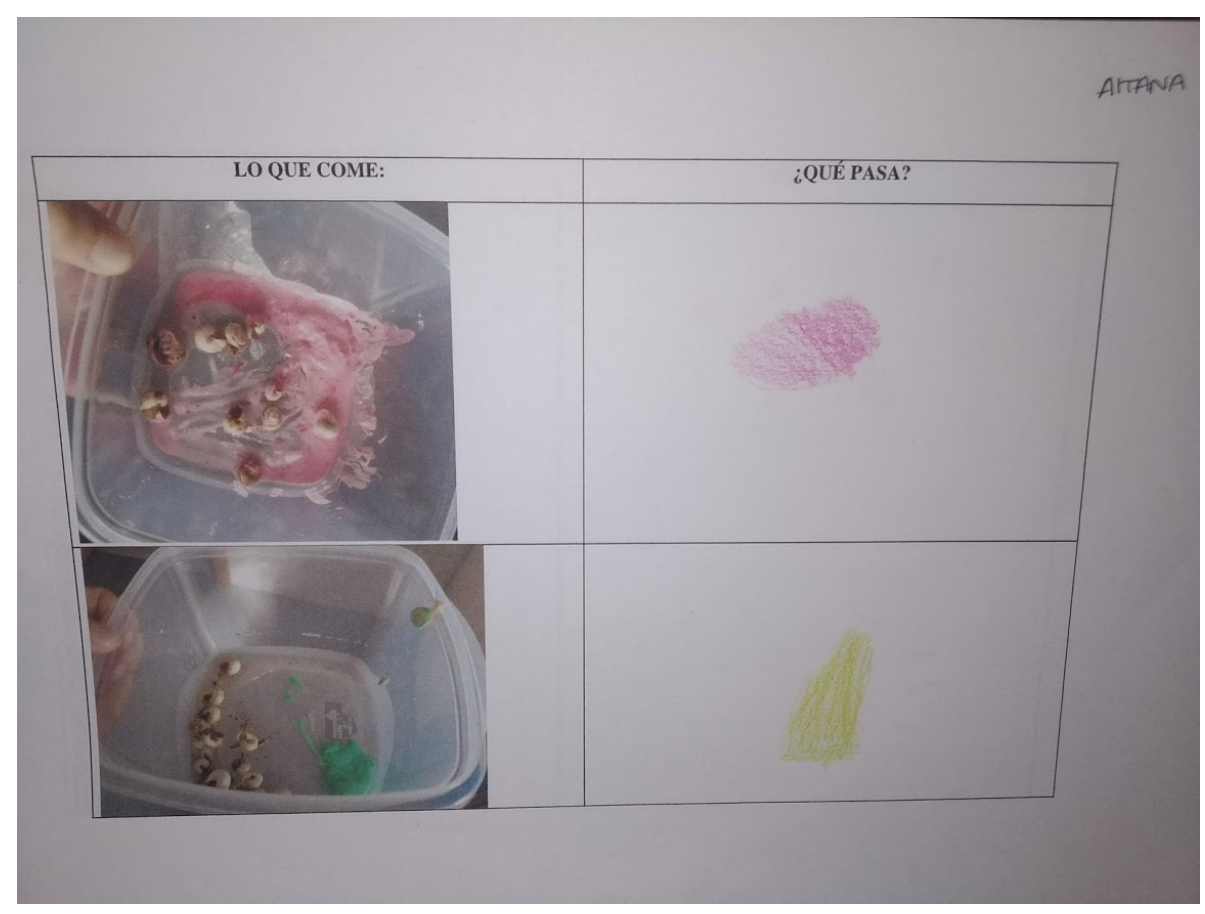

FIGURA 1

Ejemplo de tabla de resultados elaborada por los estudiantes «los caracoles que han comido harina con colorante rojo han hecho caca de color rosa y los que han comido harina con colorante verde han hecho caca de color verde»

Se recogieron 24 tablas con los resultados observados, ya que hubo una falta de asistencia y se clasificaron según sus respuestas. A modo de ejemplo se muestra la frecuencia de resultados observados por el alumnado del grupo rojo, en la tabla 4. Dibujaron los resultados correctamente 20/24 escolares, pues vieron que las heces de los caracoles eran del mismo color que lo que comían. Una niña, además, observó que el color de los caracoles también era del color de la comida, al ser su piel translúcida y poderse observar en su interior el alimento de cada color.

Sin embargo, 4 alumnos dibujaron el excremento de los caracoles que comieron harina con colorante rojo de color rojo. Llama la atención cómo no cambiaron sus hipótesis iniciales, a pesar de que la realidad observada las contradecía.

TABLA 4

Frecuencia de resultados observados por los escolares sobre el color del excremento del caracol tras ingerir harina con colorante rojo

\begin{tabular}{lc}
\hline Resultados observados sobre el color excremento & Frecuencia \\
\hline Es del mismo color que la comida (rosa). & $19 / 24$ \\
Es rosa y además aprecia que el caracol entero se ve del mismo color, al ser traslúcido. & $1 / 24$ \\
Es del color del colorante que forma parte de la comida (caca roja). & $4 / 24$ \\
\hline
\end{tabular}

$\mathrm{Al}$ poner en común los resultados obtenidos, se procedió a compararlos con las hipótesis iniciales. En el caso del colorante verde, los resultados coincidían con las hipótesis de los niños, las heces eran verdes. Con respecto al colorante rojo, la mayoría de los estudiantes se dio cuenta de que los resultados no coincidían con lo que pensaban que iba a pasar (13/24) o confirmaron sus hipótesis iniciales (7/24).

6) Explicación de la docente utilizando la modelización como recurso didáctico. La maestra construyó un modelo del sistema digestivo humano, para explicar la relación entre la alimentación y la excreción animal. 
Los materiales necesarios para la construcción del modelo se detallan en la tabla 5 y el modelo elaborado se aprecia en la figura 2.

TABLA 5

Materiales necesarios para el diseño de la maqueta del sistema digestivo

\begin{tabular}{lll}
\hline 1 tablón de cartón-pluma $50 \times 70 \mathrm{~cm}$. & 2 bolsas zip & 1 cinta adhesiva (Fixoß) \\
1 goma EVA rosa A4 & 1 calcetín de lana marrón & 1 pistola de silicona \\
2 folio blanco A4 & 2 pinzas & 1 tubo de silicona \\
1 tijeras & 6 galletas & 1 rotulador verde \\
3 bridas transparentes & 1 embudo & 1 rotulador rosa \\
1 lámina de acetato A4 (se enrolla & $50 \mathrm{ml}$ de agua & 1 rotulador permanente negro \\
para simular el esófago) & & 1 bote de cola blanca \\
1 fotocopia en folio A4 & 1 cubo de plástico & 1 \\
\hline
\end{tabular}

a)

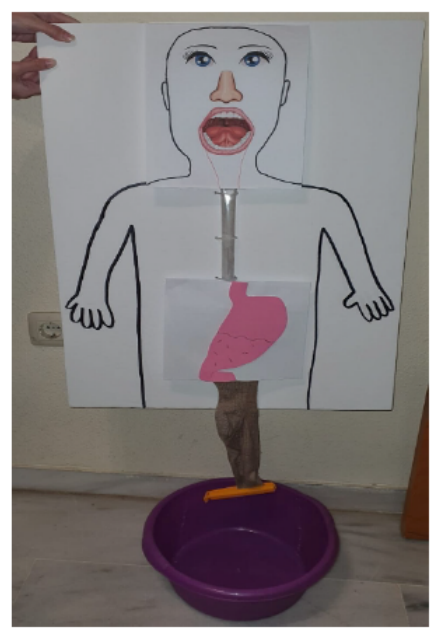

b)

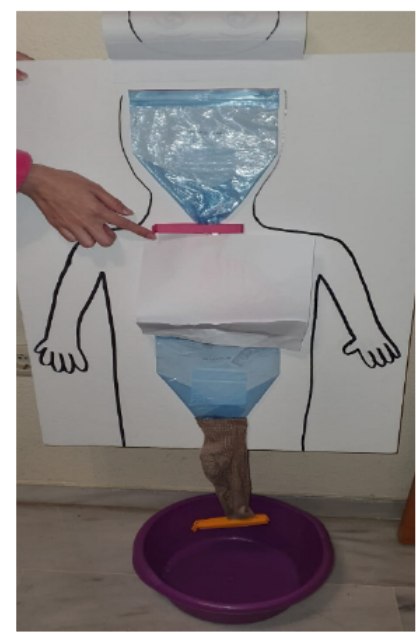

FIGURA 2

a) Modelo del sistema digestivo visto desde fuera; b) Modelo del sistema digestivo, desde dentro (abriendo las solapas de la boca y del estómago)

La docente explicó al alumnado que, igual que los caracoles, el aspecto de los excrementos de las personas puede depender de lo que comamos. Si bien el color del alimento no siempre coincide con el del excremento, ciertas comidas (como la tinta negra del calamar), pueden alterar el color de aquel. Se inició así una etapa de diálogo y manipulación colaborativa de la maqueta con la que se pretendió que el alumnado construyera los modelos científicos escolares recogidos en la tabla 6. 
TABLA 6

Transposición de los modelos científicos deseables para una clase de 5 años sobre el sistema digestivo

\begin{tabular}{|c|c|}
\hline Transposición del Modelo científico deseable para el nivel de Infantil & Figura \\
\hline $\begin{array}{l}\text { El sistema digestivo esta formado por distintos organos (boca, esofago, estomago e intestino). } \\
\text { Cada uno tiene su función. Forman un sistema, porque las funciones son complementarias y } \\
\text { ocurren transformaciones. }\end{array}$ & $\begin{array}{l}2 \text { (a) } \\
\text { (b) }\end{array}$ \\
\hline $\begin{array}{l}\text { En la boca se produce la masticación y deglución. La lengua mezcla el líquido que tenemos en la } \\
\text { boca (saliva) con el alimento, facilitando la deglución (ayudándonos a tragar). }\end{array}$ & $\begin{array}{l}3 \text { (a) } \\
\text { (b) }\end{array}$ \\
\hline Para cuidar los dientes hay que lavárselos, evitando enfermedades (picaduras o caries). ${ }^{1}$ & \\
\hline En el esófago, gracias a sus músculos, se conduce el alimento mezclado con la saliva al estómago. ${ }^{1}$ & $3(\mathrm{c})$ \\
\hline $\begin{array}{l}\text { En al estómago se lleva a cabo la digestión. Ocurre gracias al movimiento de las paredes del } \\
\text { estómago y a los jugos gástricos. Los alimentos se digieren en sus nutrientes. }{ }^{1}\end{array}$ & $\begin{array}{l}3 \text { (d) } \\
\text { (e) }\end{array}$ \\
\hline $\begin{array}{l}\text { En el intestino se separan las sustancias útiles de las no aprovechables, se absorben las primeras } \\
\text { («como las vitaminas»), gracias a sus repliegues («pelitos»). Así pasan a la sangre, que los distribuye } \\
\text { por todo el cuerpo. }\end{array}$ & $3(\mathrm{f})$ \\
\hline $\begin{array}{l}\text { Todo lo que comemos no lo absorbe nuestro cuerpo. Al defecar expulsamos la parte de los } \\
\text { alimentos que no puede ser absorbida. Para ello, el intestino también tiene músculos. }\end{array}$ & 4 \\
\hline
\end{tabular}

${ }^{1}$ No se estudió la evolución en el aprendizaje de estos modelos por falta de tiempo

La docente fue realizando una explicación dialogada, con multitud de preguntas que guiaban el proceso de la digestión representado por la maqueta. Estas preguntas no se describen en el texto (por falta de espacio), pero se muestran resumidas en la tabla 7 , relacionándolas con el momento del proceso de la digestión representado con la maqueta. Además, los niños y la docente, de forma colaborativa, fueron manipulando la maqueta, introduciendo galletas en la bolsa, añadiendo agua, presionando los tubos, retirando las pinzas para dejar pasar el bolo alimenticio, etc.

\section{TABLA 7}

Preguntas realizadas en los diferentes momentos del proceso de la digestión representado con la maqueta elaborada

\begin{tabular}{|c|c|c|}
\hline $\begin{array}{l}\text { Momento del proceso } \\
\text { representado }\end{array}$ & Preguntas formuladas durante la intervención & Figura \\
\hline Masticación & $\begin{array}{l}\text { ¿Por dónde emperamos a comer?; ¿Qué pasa en la boca?; ¿Qué tenemos en la } \\
\text { boca?; ¿Qué es lo que bacemos con los dientes? }\end{array}$ & $3(\mathrm{a}) \mathrm{y}(\mathrm{b})$ \\
\hline $\begin{array}{l}\text { Deglución y paso por } \\
\text { el esófago }\end{array}$ & $\begin{array}{l}\text { ¿Qué hacemos después de masticar y de mezclar la comida con la saliva?; ¿Y cómo } \\
\text { bacemos para que se vaya por la garganta?; ¿Cómo tragamos?; ¿Sabéis que dentro } \\
\text { del cuerpo también tenemos músculos, igual que en los brazos y las piernas? }\end{array}$ & $3(\mathrm{c})$ \\
\hline Estómago & $\begin{array}{l}\text { ¿Dónde están abora las galletas?; ¿Sabéis qué ocurre en el estómago? (nadie lo } \\
\text { sabía y querian saberlo). }\end{array}$ & $3(d)$ y (e) \\
\hline Intestino & $\begin{array}{l}\text { ¿Sabéis cómo se llama el órgano al que pasa abora la pasta? (no lo sabían); } \\
\text { ¿Sabéis a dónde pasa el líquido y los nutrientes que salen del intestino (calcetín)? } \\
\text { (no lo sabían y querían saberlo). }\end{array}$ & $3(\mathrm{f})$ \\
\hline Excreción & ¿Todo lo que comemos lo absorbe el cuerpo? ¿Todo pasa a la sangre? & 4 \\
\hline
\end{tabular}



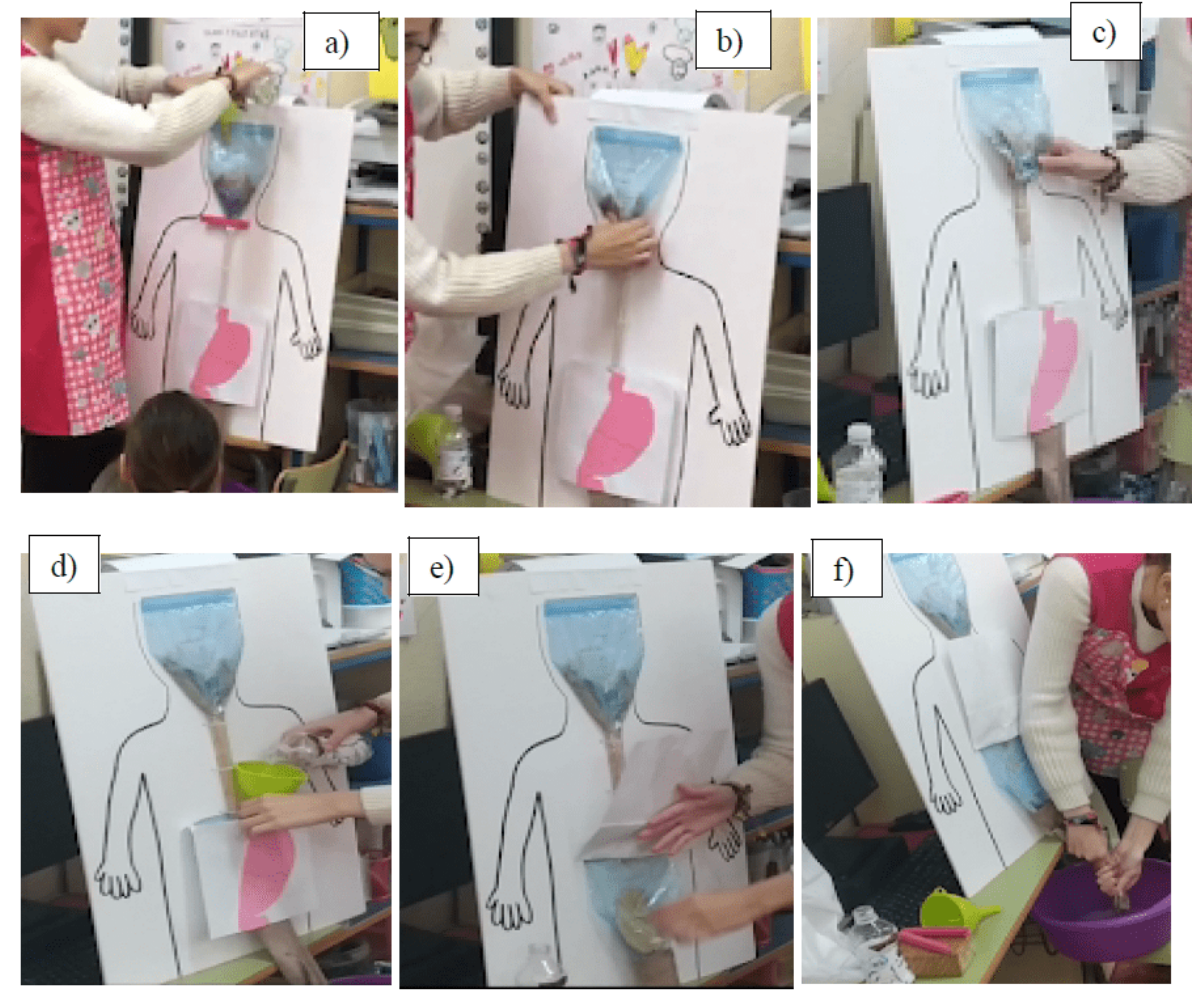

FIGURA 3

a) Mezcla de galleta con «saliva»; b) Masticación; c) Deglución y paso por el esófago; d) Jugos gástricos en el estómago; e) Movimientos gástricos; f) Absorción de nutrientes en el intestino

Es importante clarificar que, como todo modelo, la maqueta diseñada tenía ciertas limitaciones. Por ejemplo, la absorción de los nutrientes se representó exprimiendo el calcetín, de tal manera que los niños observaban cómo la pasta quedaba en él (que al abrir la pinza final saldría a modo de heces, figura 4) y el agua salía del apartado digestivo (a modo de sangre con los nutrientes que iba a circular por nuestro cuerpo). Para evitar afianzar la idea alternativa del intestino como un colador con agujeros, se insistió en la presencia de vellosidades intestinales, como «pelitos absorbentes», que recogen esos nutrientes y son los responsables de su absorción. Por otro lado, la falta de tiempo hizo que los modelos construidos no se relacionaran con ideas necesarias para evitar la idea errónea, aunque muy extendida, de que la nutrición solo está relacionada con el sistema digestivo. Creemos que para evitar esto, sería muy conveniente trabajar los sistemas respiratorio y circulatorio (en nuestro caso no fue posible, por las necesidades del centro escolar). 


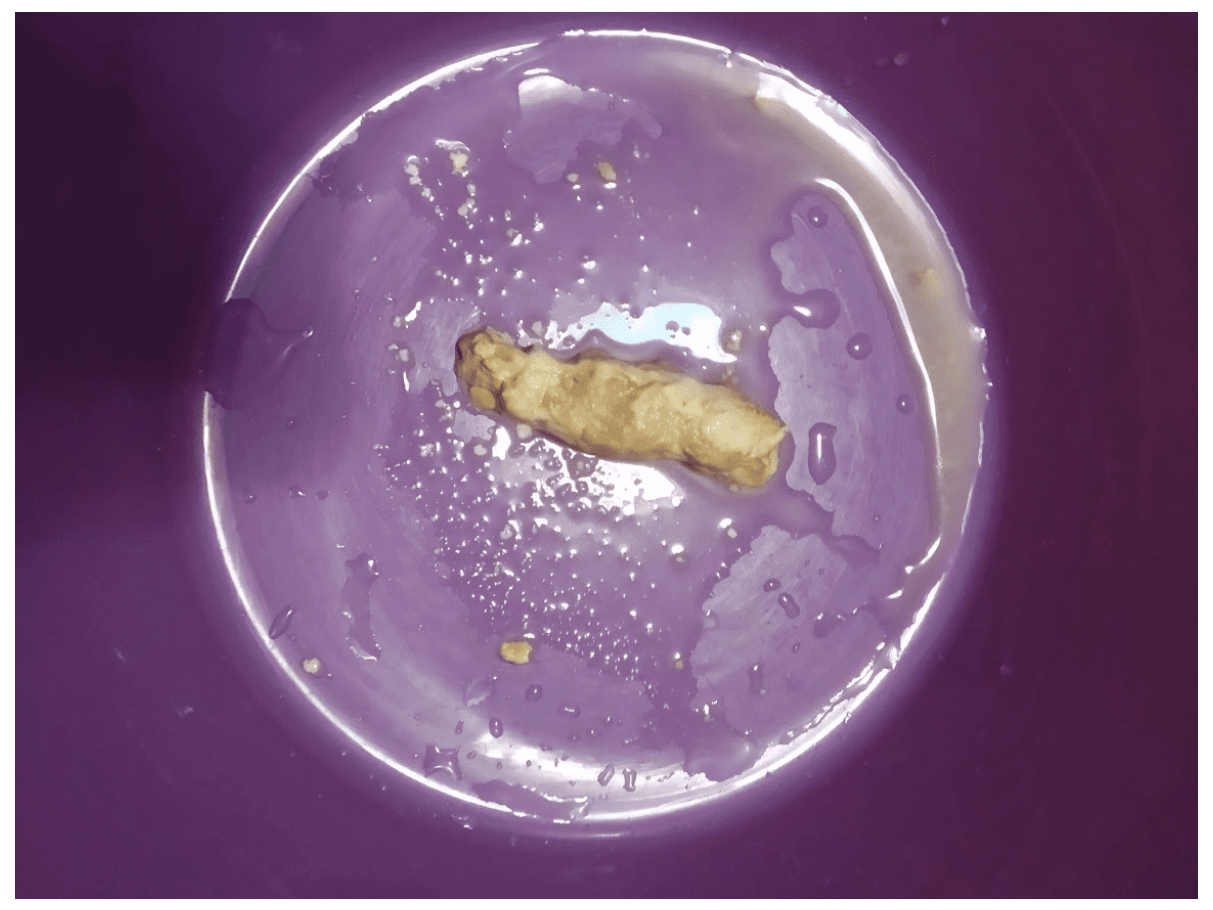

FIGURA 4

Pasta resultante a modo de «heces» que salieron al final del proceso de la digestión seguido con el modelo

7) Elaboración y comunicación de conclusiones. Tras esta explicación, la profesora comentó que había venido Caperucita Roja y la abuelita (se presentaron las marionetas), y se teatralizó siguiendo un diálogo preparado previamente. En él, la abuelita comenta que el día anterior había comido lentejas y cuando después fue al cuarto de baño, «en su caca había pellejitos de lenteja». Buscando la causa del problema, Caperucita pide ayuda a los estudiantes de la clase, ya que ellos «han hecho un experimento con caracoles y han visto qué ocurre en el cuerpo por dentro cuando comemos o hacemos caca». En la tabla 8 se aprecian las respuestas del alumnado a todas las cuestiones que Caperucita les plantea y la proporción de las mismas en el aula. La abuelita se despide agradeciendo la ayuda y resumiendo todo lo que había aprendido con ellos.

TABLA 8

Preguntas realizadas a los escolares, sus respuestas y proporciones de las mismas

\begin{tabular}{|c|c|c|}
\hline Preguntas & Opciones a responder (mano en cabeza o alzada) & Proporción \\
\hline \multirow{2}{*}{$\begin{array}{l}\text { ¿Por dónde pasaron las lentejas que } \\
\text { comió la abuelita? }\end{array}$} & Pasaron por boca, esófago, estómago e intestino & $20 / 24$ \\
\hline & Pasaron por boca, pulmones y estómago & $2 / 24$ \\
\hline \multirow{2}{*}{$\begin{array}{l}\text { ¿Qué pasó en la boca de la } \\
\text { abuelita? }\end{array}$} & Se metió las lentejas en la boca y las tragó sin masticar & $4 / 24$ \\
\hline & Se mezclaron con la saliva en la boca y las masticó & $18 / 24$ \\
\hline \multirow{2}{*}{$\begin{array}{l}\text { Cuando las lentejas llegaron al } \\
\text { intestino, ¿el cuerpo se quedó todas } \\
\text { o echó algunas en la «caca»? }\end{array}$} & $\begin{array}{l}\text { El cuerpo absorbió lo que pudo y expulsó por la caca algunos } \\
\text { trocitos de lentejas }\end{array}$ & $19 / 24$ \\
\hline & $\begin{array}{l}\text { El cuerpo absorbió todas las lentejas y no expulsó nada } \\
\text { de ellas por la caca }\end{array}$ & $5 / 24$ \\
\hline
\end{tabular}

\section{Grado de interés del alumnado por los contenidos de Ciencias trabajados}

No solo las marionetas contribuyeron a captar el interés de los escolares, sobre todo, el hecho de sentirse «científicos y científicas» y «hacer experimentos». Se implicaron en la actividad, les ilusionaba tocar caracoles vivos y darles de comer. Durante la semana en la que se llevó a cabo el experimento se acercaron a 
ver los caracoles en múltiples ocasiones y les fascinó verlos comer en directo (se ve claramente el color de la harina entrando por su cuerpo, ya que los caracoles tienen una piel translúcida).

Lo que sí resultó confuso para algunos estudiantes fue que al darle a un grupo de caracoles harina con colorante rojo, la mezcla resultante fuera rosa y, por tanto, las heces también. Fue evidente que las heces del caracol que come harina con colorante verde fueran verdes; pero en el otro caso les confundió el cambio de color del colorante al unirse a la harina. En cualquier caso, el color rosa del alimento como un resultado de la experimentación que contradice las predicciones realizadas les ayudó a vivenciar el método científico y sus sorpresas.

Durante la explicación dialogada y la manipulación colaborativa de la maqueta, el interés por participar fue muy alto, así como los consensos para acordar las acciones a realizar con la maqueta.

\section{Evolución del aprendizaje tras el proceso instructivo}

En este apartado se muestra la evolución de los modelos científicos escolares del alumnado sobre el sistema digestivo al finalizar la actividad implementada en el aula. Esta evolución se presenta en las tablas 9 a 11. Los descriptores de las respuestas finales aparecen en cursiva.

TABLA 9

Evolución de los modelos escolares sobre los órganos del sistema digestivo

\begin{tabular}{|c|c|c|c|}
\hline \multicolumn{4}{|c|}{ ¿Sabéis qué son y cómo se llaman? ¿Qué ocurre en cada uno? } \\
\hline Niveles de formulación & Descriptores de baja inferencia & $\begin{array}{l}\text { Frecuencia } \\
\text { inicial }\end{array}$ & $\begin{array}{l}\text { Frecuencia } \\
\text { final }\end{array}$ \\
\hline I. No saben/no contestan & $\begin{array}{l}\text { "El esqueleto humano»; «El cerebro» } \\
\text { (señala intestino)». }\end{array}$ & $4 / 25$ & $2 / 24$ \\
\hline $\begin{array}{l}\text { II. Solo reconocen un } \\
\text { órgano del sistema digestivo, } \\
\text { la boca, que sirve para } \\
\text { comer. }\end{array}$ & $\begin{array}{l}\text { «Una boca, para comen»; «E1 cerebro } \\
\text { (señalando el intestino), la boca (señala la } \\
\text { boca) y los pulmones (señala el esófago y el } \\
\text { estómago)». }\end{array}$ & $19 / 25$ & - \\
\hline $\begin{array}{l}\text { III. No solo la boca, también } \\
\text { conocen dónde está el } \\
\text { intestino o el estómago. }\end{array}$ & "por la boca, los pulmones y estómaga". & $1 / 25$ & $2 / 24$ \\
\hline $\begin{array}{l}\text { IV. Además, saben el } \\
\text { recorrido que sigue la } \\
\text { comida, aunque no detallen } \\
\text { la función o nombre de cada } \\
\text { órgano. }\end{array}$ & «por la boca, el esófago, el estómago y el intestino». & $1 / 25$ & $20 / 24$ \\
\hline
\end{tabular}


TABLA 10

Evolución de los modelos escolares sobre la saliva y su utilidad

\begin{tabular}{|c|c|c|c|}
\hline \multicolumn{4}{|c|}{ ¿Nuestra boca está seca o mojada por dentro? ¿Por qué está mojada? ¿Para qué creéis que tenemos saliva en la boca? } \\
\hline Niveles de formulación & Descriptores de baja inferencia & $\begin{array}{c}\text { Frecuencia } \\
\text { inicial }\end{array}$ & $\begin{array}{c}\text { Frecuencia } \\
\text { final }\end{array}$ \\
\hline I. No saben/no contestan & «Mojada. No lo sé»; «Está seca». & $11 / 25$ & $6 / 24$ \\
\hline $\begin{array}{l}\text { II. Saben que tenemos } \\
\text { líquido en la boca. }\end{array}$ & $\begin{array}{l}\text { «stá seca. (Se toca) ¡Ah, no, está mojada! Porque } \\
\text { está limpia. Es líquido». }\end{array}$ & $1 / 25$ & - \\
\hline $\begin{array}{l}\text { III. Al líquido lo llaman } \\
\text { «babas». }\end{array}$ & «Está mojada. Por la baba». & $2 / 25$ & - \\
\hline $\begin{array}{l}\text { IV. Conocen que el líquido } \\
\text { se llama saliva. }\end{array}$ & $\begin{array}{l}\text { «Mojada. Por la saliva. Para que así la boca no esté } \\
\text { seca». }\end{array}$ & $7 / 25$ & - \\
\hline $\begin{array}{l}\text { V. Saben que la saliva sale } \\
\text { de debajo de la lengua. }\end{array}$ & $\begin{array}{l}\text { «La lengua está mojada. Por la saliva. ¿Sabes una } \\
\text { cosa del cuerpo? Debajo de la lengua hay unos } \\
\text { agujeritos por donde sale la saliva». }\end{array}$ & $2 / 25$ & - \\
\hline $\begin{array}{l}\text { VI. Saben que la saliva y se } \\
\text { mezcla con el alimento } \\
\text { facilitando la formación y } \\
\text { deglución del bolo } \\
\text { alimenticio. }\end{array}$ & $\begin{array}{l}\text { "Por la saliva. Para tragar las cosas»; "Las lentejas se } \\
\text { mezclaron con la saliva en la bocay las mastico". }\end{array}$ & $2 / 25$ & $18 / 24$ \\
\hline
\end{tabular}

TABLA 11

Evolución de los modelos escolares sobre la absorción y excreción de los alimentos

\begin{tabular}{|c|c|c|c|}
\hline \multicolumn{4}{|c|}{$\begin{array}{l}\text { Si te comes algo por la boca (una cbuche, una zanahoria, espinacas...), jcreéis que parte de ese alimento puede salir por la caca o } \\
\text { todo se queda dentro de nosotros? }\end{array}$} \\
\hline Niveles de formulación & Descriptores de baja inferencia & $\begin{array}{l}\text { Frecuencia } \\
\text { inicial }\end{array}$ & $\begin{array}{l}\text { Frecue } \\
\text { ncia } \\
\text { final }\end{array}$ \\
\hline I. No saben/no contestan & & $3 / 25$ & $1 / 24$ \\
\hline $\begin{array}{l}\text { II.a. Creen que todo lo que } \\
\text { comemos lo absorbe nuestro } \\
\text { cuerpo. }\end{array}$ & $\begin{array}{l}\text { «Todo se queda dentro de nuestro cuerpo»; «no } \\
\text { expulsa nada de lentejas por la caca, el cuerpo absorbe } \\
\text { todas las lentejas». }\end{array}$ & $13 / 25$ & $4 / 24$ \\
\hline $\begin{array}{l}\text { II.b. Creen que todo lo que } \\
\text { comemos, lo expulsamos del } \\
\text { organismo. }\end{array}$ & $\begin{array}{l}\text { «ues yo creo que cuando bebo algo es el pipí y } \\
\text { cuando como algo es la caca. Sale por la caca». }\end{array}$ & $6 / 25$ & - \\
\hline $\begin{array}{l}\text { III. Entienden que el cuerpo } \\
\text { absorbe los alimentos y también } \\
\text { los defeca, pero sin entender qué } \\
\text { parte del alimento se absorbe y } \\
\text { qué parte lo defecamos. }\end{array}$ & $\begin{array}{l}\text { «Hay una cosa diferente... que si comemos } \\
\text { muchas cosas nos sale mucha caca, pero si } \\
\text { comemos pocas cosas se nos queda en la } \\
\text { barriga». }\end{array}$ & $1 / 25$ & - \\
\hline $\begin{array}{l}\text { IV. Saben que todo lo que } \\
\text { comemos no lo absorbe nuestro } \\
\text { cuerpo, sino que parte de los } \\
\text { alimentos se expulsa al defecar. }\end{array}$ & $\begin{array}{l}\text { «Un poco se queda dentro y otro poco sale por } \\
\text { la caca»; «el cuerpo absorbió lo que pudo y expulsó por } \\
\text { la caca algunos trocitos de lenteja». }\end{array}$ & $2 / 25$ & $19 / 24$ \\
\hline
\end{tabular}

\section{DiSCUSIÓN Y CONCLUSIONES}

En este estudio se ha implementado una actividad experimental de carácter indagador que utiliza la modelización como recurso didáctico. Para desarrollar las transposiciones didácticas de los modelos de ciencia escolar a construir, nos basamos en las recomendaciones de distintos autores (p.e. Bahamonde y 
Gómez-Galindo 2016, Contento 1981, Cubero 1988, Reiss et al. 2002), confiando en las capacidades del alumnado de Infantil e intentando evitar concepciones alternativas estudiadas sobre el sistema digestivo en edades infantiles y posteriores, tales como el desconocimiento de los nutrientes (saben que la leche, verduras y fruta son saludables, pero no saben justificarlo), creer que la comida nunca sale del cuerpo, a no ser que sea oralmente (vomitando), o que el intestino actúa a modo de colador por el que los nutrientes pasan a la sangre. Para estudiar la eficacia de la actividad, se han comparado los modelos científicos escolares iniciales del alumnado de 5 y 6 años sobre el sistema digestivo con los presentados al finalizar la actividad. Se ha comprobado la evolución positiva del aprendizaje del alumnado, así como la motivación e interés que ha suscitado la intervención didáctica. La modelización en su versión instrumental ha permitido hacer perceptibles contenidos a priori abstractos en EI. El carácter indagador de la actividad ha potenciado la capacidad de observación de los escolares y su interés por la manipulación.

Por todo, los resultados de este estudio han sido satisfactorios, al igual que los de las secuencias didácticas presentadas por Siry y Kremer (2011) para Infantil. En ambos casos, la manipulación, la indagación y el uso de modelos en esta etapa educativa han conseguido hacer evolucionar los modelos de ciencia escolar de los pequeños.

Por otro lado, y con respecto a la capacidad de los estudiantes para formular conjeturas o hipótesis, hemos visto cómo estudiantes de 5 años pueden realizarlas, corroborando lo que algunos estudios señalan ya desde los 4 años (Kohlhauf et al. 2011). Concretamente, hemos obtenido, en un aula de 24 estudiantes, cinco hipótesis diferentes a la pregunta de indagación de la actividad que exponemos. Coincidimos, por tanto, con Herakleioti y Pantidos (2016), ya que conseguimos que el alumnado de Infantil realice sus predicciones y las comprueben de forma experimental.

$\mathrm{Al}$ igual que Solé-Llussà et al. (2018), comprobamos las bondades de esta secuencia de carácter indagador en el aprendizaje de las ciencias experimentales, tales como el desarrollo en los escolares de habilidades de: observación, realización de predicciones, planificación de la experimentación, comprobación experimental, análisis de resultados y comunicación de las conclusiones obtenidas. En todas las fases de la indagación, los escolares son protagonistas y tienen un papel activo, siendo el papel de guía de la docente fundamental. Además, la última fase nos es útil para conocer los modelos científicos escolares finales de los estudiantes, lo que permite el diseño de nuevas intervenciones docentes si fuese necesario.

Hemos comprobado cómo es conveniente trabajar en el aula las temáticas que interesan a los estudiantes. De forma similar a Canedo-Ibarra et al. (2012), en este estudio la intervención docente se ha llevado a cabo con organismos vivos, foco de gran interés para los estudiantes de EI. Además, comer es un acto voluntario (algo que no ocurre con la respiración, dentro de la nutrición). Toyama (2020) afirmaba que los niños pueden estar más interesados en los procesos mecánicos como la digestión frente a procesos involuntarios como la respiración, ya que sobre parte de aquellos tienen control voluntario (como la masticación o la deglución). Así mismo, en nuestra propuesta se han utilizado marionetas que narraban una historia relacionada con la temática. Coincidimos con Orellana y Espinet (2009), quienes valoran el cuento como recurso facilitador de la modelización para la enseñanza de la ciencia en EI.

Además, la experimentación y la modelización instrumental parecen ser muy motivadoras para el alumnado de EI. Rodríguez-Moreno et al. (2020) implementaron una actividad experimental acompañada de escenificación, y de la misma forma que la suya, para nuestro alumnado la propuesta implementada (en la que la experimentación se complementó con una maqueta del sistema digestivo) fue más divertida que las actividades que acostumbraban a hacer. El clima del aula fue de implicación e interés.

Otros autores han utilizado modelos instrumentales en EI para trabajar el cuerpo humano, como Fuentes (2016), quien utilizó un cuerpo humano a tamaño natural en las actividades de su proyecto para trabajar las partes del cuerpo (internas y externas), o De Alba y Ramos (2020), quienes enriquecieron el modelo científico escolar del alumnado de EI sobre el sistema circulatorio con la realización de dibujos, siluetas del cuerpo y la manipulación de ciertos órganos. También, Padial-Ruz et al. (2017) con sus maquetas (dentadura gigante), 
entre otros recursos, obtuvieron una evolución positiva de los aprendizajes. Creemos que el conocimiento del propio cuerpo es necesario para el escolar en su etapa educativa inicial, ya que su propio cuerpo es una de sus prioridades, por lo que este conocimiento puede darle autoestima y felicidad.

Las intervenciones didácticas en EI no siempre consiguen que el alumnado construya el modelo científico deseable, tal como describen Rodríguez-Moreno et al. (2020), ya que, aunque sus resultados fueron satisfactorios, no consiguieron que el alumnado tuviera el modelo deseable de corriente eléctrica. En nuestro caso, podemos decir que en general, los estudiantes fueron capaces de elaborar un modelo del sistema digestivo deseable para la etapa de EI. Así, pasaron de conocer únicamente la boca como órgano del mismo, a conocer el recorrido del alimento por él, la utilidad de la saliva en el proceso y conectaron la digestión con procesos de absorción y excreción.

A pesar de ello, nuestra propuesta tiene ciertas limitaciones. Hubiera sido deseable disponer de un mayor número de sesiones de clase para llevar a cabo una intervención educativa más profunda sobre los modelos y la modelización aplicados a los niveles educativos elementales. Además, cuando se habla del modelo de ser vivo, se entiende está constituido a su vez por tres sub-modelos: Nutrición, Reproducción y Relación, que deberían trabajarse en las aulas de forma articulada (Bahamonde y Gómez-Galindo 2016). Al tratar el modelo de órganos del sistema digestivo, se debería relacionar con la función de nutrición, para aumentar la comprensión de un fenómeno vital y no solo la memorización o conocimiento desarticulado de una serie de órganos o eventos aislados.

Sin embargo, la breve intervención respondía a la necesidad de integrar la intervención en el programa de la asignatura, que solo cuenta con 60 horas de clase, y que incluye otros muchos contenidos y objetivos educativos. Además, algunos autores (e.g., Leach, Hind y Ryder 2003; García-Carmona y Acevedo-Díaz 2017) defienden las intervenciones cortas porque, además de ajustarse a la realidad habitual de las clases de ciencia escolar, pueden motivar al profesorado a plantearlas dentro de su programación generalmente sobrecargada de temas y actividades.

A pesar de ello, creemos que este estudio puede ayudar a incrementar el conocimiento sobre el desarrollo de las prácticas científicas en el aula de Infantil. Se ha comprobado que el alumnado del segundo ciclo de EI puede llevar a cabo indagaciones estructuradas y que la modelización puede ayudar al docente a hacer viables elementos o fenómenos difíciles de entender en la etapa de Educación Infantil. Como posibles futuras líneas de trabajo, se podría investigar si los niños de los primeros niveles educativos son capaces de llevar a cabo indagaciones abiertas sobre la digestión, por ejemplo, al plantearles el reto de diseñar cómo investigar si la saliva produce cambios en los alimentos.

\section{Agradecimientos}

Este estudio forma parte del proyecto de I+D EDU2017-82505-P, financiado por el Ministerio de Economía, Industria y Competitividad (Gobierno de España).

\section{REFERENCIAS BIBLIOGRÁFICAS}

Acevedo-Díaz, J.A, García-Carmona, A., Aragón-Méndez, M, M. y Oliva-Martínez, J.M. (2017). Modelos científicos: significado y papel en la práctica científica. Revista Cientifica, 30(3), 155-166.

Adúriz-Bravo A. (2001) Integración de la epistemología en la formación inicial del profesorado de ciencias (Tesis doctoral). Universidad Autónoma de Barcelona.

Aragón-Núñez L., Jiménez-Tenorio N., Oliva-Martínez J.M. y Aragón-Méndez L. (2018) La modelización en la enseñanza de las ciencias: criterios de demarcación y estudio de caso. Revista Científica, 32(2), 193-206. https: //doi.org/10.14483/23448350.12972

Ashbrook P. (2012) The Early Years: Seeing the Moon. Science and Children, 49(5), 26-27. 
B.O.E. (2008) Orden ECI/3960/2007, de 19 de diciembre, por la que se establece el currículo y se regula la ordenación de la educación infantil. Núm. 5, de 5 de enero de 2008, pp.1016-1036. https://www.boe.es/boe/dias/2008/0 1/05/pdfs/A01016-01036.pdf

Bahamonde N. y Gómez Galindo A. A. (2016) Caracterización de modelos de digestión humana a partir de sus representaciones y análisis de su evolución en un grupo de docentes y auxiliares académicos. Enseñanza de las Ciencias, 34(1), 129-147.http://dx.doi.org/10.5565/rev/ensciencias.174 Barak, M.y Hussein-Farraj, R. (2013).

Banchi H. y Bell R. (2008) The Many Levels of Inquiry. Science and Children, 46(2), 26-29.

Calo, N., García-Rodeja, I. y Sesto, V. (2021). Construyendo conceptos sobre electricidad en infantil mediante actividades de indagación. Enseñanza de las Ciencias, 39(2), 223-240.

Canedo-Ibarra S.P., Casterlló-Escandell J.C., García-Wehle P., Gómez-Galindo A.A. y Morales-Blake A.R. (2012) Cambio conceptual y construcción de modelos científicos precursores en educación infantil. Revista Mexicana de Investigación Educativa, 17(54), 691-727.

Contento I. (1981) Children's thinking about food and eating. A piagetian-based study. Journal of Nutrition Education, 13, 86-90.

Couso D. (2014) De la moda de «aprender indagando» a la indagación para modelizar: una reflexión crítica. Ponencia presentada en los 26 Encuentros de Didáctica de las Ciencias Experimentales, Huelva, España. https://encuent rodedidcticadelamatemticayciencias.files.wordpress.com/2015/12/couso-2014.pdf

Cruz-Guzmán M., García-Carmona A. y Criado A. M. (2017). Aprendiendo sobre los cambios de estado en Educación Infantil mediante secuencias de pregunta - predicción - comprobación experimental. Enseñanza de las Ciencias, 35(3), 175-193. https://doi.org/10.5565/rev/ensciencias.2336

Cubero R. (1988) Los esquemas de los niños: Un estudio sobre el proceso digestivo. Cuadernos de Pedagogía, 165, 57-60.

De Alba V. y Ramos S.L. (2020) Modelización científica escolar para explorar el sistema circulatorio en Educación Infantil. Enseñanza de las Ciencias, 38(1), 105-125.126. https://doi.org/10.5565/rev/ensciencias.2765

Díaz-Moreno, N. (2017). ¿Cómo trabajar indagación en el aula de Infantil? Análisis de las debilidades y fortalezas de los maestros en formación. Enseñanza de las Ciencias, nº extraordinario, 1965-1970.

Fuentes M.C. (2016) Proyecto del cuerpo humano mediante el uso de las TIC's (Trabajo Fin de Grado). Universidad de Jaén: Facultad de Humanidades y Ciencias de la Educación, Jaén (España).

Galagovsky L.R. y Adúriz-Bravo A. (2001) Modelos y analogías en la enseñanza de las ciencias naturales. El concepto de modelo didáctico analógico. Enseñanza de las Ciencias, 19(2), 231-242.

García-Carmona A. y Acevedo-Díaz J.A. (2017) Comprensión de futuro profesorado de ciencia del concepto de teoría científica a partir de la controversia Pasteur-Liebig sobre la fermentación. Enseñanza de las ciencias, Número extra 0, 3703-3708.

Gilbert J.K. (2004) Models and modelling: Routes to more authentic science education. International Journal of Science and Mathematics Education, 2(2), 115-130. https://doir.org/10.1007/s10763-004-3186-4

Gómez-Galindo A.A., Sanmartí N. y Pujol R.M. (2007) Fundamentación teórica y diseño de una unidad didáctica para la enseñanza del modelo ser vivo en la escuela primaria. Enseñanza de las Ciencias, 25(3), 325-340. https:/ /ddd.uab.cat/pub/edlc/02124521v25n3/02124521v25n3p325.pdf

Harrison A.G. y Treagust D.F. (2000) A typology of school science models. International Journal of Science Education, 22(9), 1011-1026. https://doi.org/10.1080/095006900416884

Herakleioti E. y Pantidos P. (2016) The Contribution of the Human Body in Young Children's Explanations about Shadow Formation. Research in Science Education, 46(1), 21-42.

Justi, R. (2006). La enseñanza de ciencias basada en la elaboración de modelos. Enseñanza de las Ciencias, 24(2), 173-184.

Kohlhauf L., Rutke U. y Neuhaus B. J. (2011) Influence of previous knowledge, language skills and domain-specific interest on observation competency. Journal of Science Education and Technology, 20, 667-678. 
Leach J., Hind A. y Ryder J. (2003) Designing and evaluating short teaching interventions about the epistemology of science in high school classrooms. Science Education, 87 (6), 831-848.

Martí, J. (2012) Aprender ciencias en la educación primaria. Barcelona: Graó.

Martínez-Chico M., López-Gay R. y Jiménez-Liso M.R. (2015) Efecto de un programa formativo para enseñar ciencias por indagación basada en modelos, en las concepciones didácticas de los futuros maestros. Revista Eureka sobre Enseñanza y Divulgación de las Ciencias, 12(1), p. 149. https://doi.org/10.25267/Rev_Eureka_ensen_divulg_ cienc.2015.v12.11.10

Mazas, B., Cascarosa, E. y Mateo, E. (2021). ¿Qué suena dentro de tu cuerpo? Un proyecto sobre el corazón en Educación Infantil. Enseñanza de las Ciencias, 39(2), 201-221.

Mosquera I., Puig B. y Blanco P. (2018) Las prácticas científicas en infantil. Una aproximación al análisis del currículum y planes de formación del profesorado de Galicia. Enseñanza de las Ciencias, 36(1), 7-23.

Oliva J.M. (2019) Distintas acepciones para la idea de modelización en la enseñanza de las ciencias. Enseñanza de las ciencias, 37 (2), 5-24. https://doi.org/10.5565/rev/ensciencias. 2648

Orellana M. y Espinet M. (2009) Los cuentos como una herramienta para la modelización compleja del entorno en la formación inicial de maestros de ciencias. Enseñanza de las Ciencias, Número Extra VIII Congreso Internacional sobre Investigación en Didáctica de las Ciencias, Barcelona, 2733-2737. http://ensciencias.uab.es/congreso09/ numeroextra/art-2733-2737.pdf

Padial-Ruz R., Ubago-Jiménez J.L., Espejo-Garcés T., Puertas-Molero P., Chacón-Cuberos R. y Moreno-Arrebola R. (2017) Promoción de hábitos saludables en el segundo ciclo de educación infantil: una propuesta a través del movimiento. Revista de Transmisión del Conocimiento Educativo y de la Salud, 9(4), 693-712 file://C:/Users/ esthe/Downloads/2017-TRANCES2.pdf

Padilla M.T. (2002) Técnicas e instrumentos para el diagnóstico y la evaluación educativa. Madrid, Spain: CCS.

Pérez G., Gómez-Galindo A.A. y González-Galli L. (2018) Enseñanza de la evolución: fundamentos para el diseño de una propuesta didáctica basada en la modelización y la metacognición sobre los obstáculos epistemológicos. Revista Eureka sobre Enseñanza y Divulgación de las Ciencias, 15(2), 2102. https://doi.org/10.25267/Rev_Eur eka_ensen_divulg_cienc.2018.v15.i2.2102

Piaget J. e Inhelder B. (1959) La genèse des structureslogiques élémentaires. París: Niestlé.

Reiss M.J., Tunnicliffe S.D., Moller A, Bartoszeck A, Carvalho G., Chen S.Y., Jarman R., Jónsson S., Manokore V., Marchenko N., Mulemwa J. y Novikova T. (2002) An international study of young peoples' drawings of what is inside themselves. Journal of Biological Education, 36, 58-64. https://doi.org/10.1080/00219266.2002.9655 802.

Rodríguez-Moreno J., de Pro C. y de Pro A. (2020) ¿Qué se puede aprender «Jugando con la electricidad» en Educación Infantil? Revista Eureka sobre Enseñanza y Divulgación de las Ciencias 17(2), 2203.

Samarapungavan A., Tippins D. y Bryan L. (2015). A Modeling-Based Inquiry Framework for Early Childhood Science Learning. In: Cabe Trundle K., Saçkes M. (Eds) Research in Early Childhood Science Education. Springer, Dordrecht. https://doi.org/10.1007/978-94-017-9505-0_12

Schwarz C.V., Reiser B.J., Davis E.A., Kenyon L., Achér A., Fortus D., Shwartz Y., Hug B. y Krajcik J. (2009) Developing a learning progression for scientific modeling: Making scientific modeling accessible and meaningful for learners. Journal of Research in Science Teaching, 46(6), 632-654. https://doi.org/10.1002/tea.20311

Siry C. y Kremer I. (2011) Children explain the rainbow: using young children's ideas to guide science curricula. Journal of Science Education and Technology, 20, 643-655.

Solé-Llussà A., Aguilar D., Ibáñez M. y Coiduras J.L. (2018) Análisis de la comunicación de experiencias indagadoras presentadas en congresos de ciencia dirigidos a alumnos de educación infantil y primaria. Revista Eureka sobre Enseñanza y Divulgación de las Ciencias 15(1), 1302. 10.25267/ Rev_Eureka_ensen_divulg_cienc.2018.v15.11.1302

Stewart J., Cartier J.L., y Passmore C.M. (2005) Developing understanding through model-based inquiry. In M. S. Donovan y J. D. Bransford (Eds.), How students learn (pp. 515-565). Washington D.C.: National Research Council. 
Sung J.Y. y Oh P.S. (2018) Sixth Grade Students' Content-Specific Competencies and Challenges in Learning the Seasons through Modeling. Research in Science Education, 48(4), 839-864. https://doi.org/10.1007/s11165-0 $16-9589-8$

Toyama N. (2000) «What are food and air like inside our bodies?»: Children's thinking about digestion and respiration. International Journal of Behavioral Development, 24. 222-230. 10.1080/016502500383359.

Wheeler, L. B., Bell, R. L., Whitworth, B. A. y Maeng, J. L. (2015). The Science ELF: Assessing the enquiry levels framework as a heuristic for professional development. International Journal of Science Education, 37(1), 55-81.

\section{Notas}

[1] Las referencias a personas o colectivos figuran en el presente trabajo en género masculino como género gramatical no marcado. Cuando proceda, se utilizarán los preceptos correspondientes en género femenino.

\section{INFORMACIÓN ADICIONAL}

Para citar este artículo: Cruz-Guzmán, M. y Martínez-Maqueda, E. (2022) Iniciación a las prácticas científicas en Educación Infantil: aprendiendo sobre el sistema digestivo por indagación basada en modelos. Revista Eureka sobre Enseñanza y Divulgación de las Ciencias 19(1), 1202. doi:10.25267/ Rev_Eureka_ensen_divulg_cienc.2022.v19.i1.1202 